\title{
Aplikasi Metode Surface Related Multiple Elimination (SRME) dan Radon Parabolik pada Data Seismik 2D Bryant Canyon Lepas Pantai Louisiana Texas
}

\author{
Selly Remiandayu*, Elistia Liza Namigo \\ Jurusan Fisika FMIPA Universitas Andalas \\ Kampus Unand, Limau Manis, Padang, 25163 \\ *Sellyremiandayu@gmail.com
}

\begin{abstract}
ABSTRAK
Multiple adalah salah satu bentuk noise yang sering muncul pada data seismik laut akibat kontras impedansi antar lapisan batuan. Keberadaan multiple pada data seismik mengakibatkan berkurangnya kualitas gambaran bawah permukaan yang dapat menyebabkan kesalahan pada saat interpretasi data, terutama untuk data seismik laut dalam dengan struktur geologi bawah permukaan yang kompleks. Salah satu metode yang digunakan dalam menghilangkan multiple adalah metode Surface Related Multiple Elimination (SRME). Metode SRME menggunakan pendekatan prediksi multiple dimana prediksi multiple ini kemudian dikurangi dengan data input sehingga didapatkan hasil data seismik yang bebas dari multiple. Metode SRME tidak memerlukan informasi bawah permukaan dan model kecepatan dalam memprediksi multiple. Pada penelitian ini metode SRME diterapkan pada 4 line dari data seismik 2D Bryant Canyon Lepas Pantai Louisiana Texas. Penelitian dilakukan dengan mengunakan software Geomage. Hasil penelitian menunjukkan bahwa metode SRME cukup efektif digunakan untuk menekan keberadaan multiple, terutama untuk jenis water-bottom multiple namun, metode ini masih belum optimal dalam mengatenuasi multiple di daerah far-offset. Oleh karena itu, pada penelitian ini juga dilakukan kombinasi metode SRME dengan metode radon parabolik untuk dapat menghilangkan multiple secara lebih optimal.

Kata kunci: multiple, metode seismik, Geomage, Surface Related Multiple Elimination (SRME), radon parabolik.
\end{abstract}

\begin{abstract}
Multiple is a form of noises that often appears in marine seismic data due to the impedance contrast among rock layers. The existence of multiple in seismic data causes a reduction in picture quality of subsurface which can cause error during data interpretation, especially for deep-sea seismic data with complex subsurface geological structure. One of the best methods to reduce multiple is Surface Related Multiple Elimination (SRME) method. SRME method uses multiple predictive approach whereas multiple prediction is then reduced by the input data to obtain the results multiple free seismic data. SRME method has advantage of not requiring subsurface information nor velocity information in comparison with other methods. In this research, SRME method applied at four lines of 2D Bryant Canyon offshore Louisiana Texas. The research is carried out by using Geomage (free-trial software). The results reveals that the SRME method is proven to be quite effective in eliminating multiple near-offset, especially for waterbottom multiple but it fails to atenuate multiple far-offset. Therefore, this research also did a combination methods between SRME and parabolic radon method to be able to eliminate multiple optimally.

Keywords: multiple, Seismic method, Geomage, Surface Related Multiple Elimination (SRME), radon parabolik.
\end{abstract}

\section{PENDAHULUAN}

Salah satu jenis gangguan yang sering muncul pada perekaman data seismik adalah multiple. Multiple merupakan pengulangan refleksi akibat terperangkapnya gelombang seismik dalam air laut atau dalam lapisan batuan lunak (Yilmaz, 1987). Multiple ini dapat berupa waterbottom multiple, peg-leg multiple, dan intra-bed multiple (Badley, 1947). Keberadaan multiple memberikan efek reflektor semu yang menyebabkan kerumitan pada saat interpretasi data. Oleh karena itu, noise multiple harus dihilangkan.

Berbagai metode telah dikembangkan untuk menghilangkan multiple pada data seismik. Beberapa metode yang umum digunakan diantaranya adalah metode dekonvolusi prediktif, $f-k$ filtering dan transformasi radon, namun ketiga metode ini masih memiliki keterbatasan. Metode dekonvolusi prediktif cukup efektif pada perairan laut dangkal namun tidak dapat digunakan untuk reflektor-reflektor yang miring (Peacock, 1969). Metode f-k filtering tidak cocok diterapkan pada near-offset, memerlukan model kecepatan, dan hanya efektif untuk struktur 
bawah permukaan yang tidak terlalu kompleks sebagaimana pada metode transformasi radon (Stewart, 2004). Berangkat dari keterbatasan itu, Verschuur dkk,. (1992) memperkenalkan metode Surfaced Related Multiple Elimination (SRME) untuk digunakan pada data seismik laut dalam dan struktur kompleks. Berbeda dengan metode-metode sebelumnya, metode SRME tidak memerlukan informasi bawah permukaan lain dan tidak memerlukan model kecepatan. Karena kepraktisan ini, metode SRME ini sangat populer di industri migas dalam satu dekade terakhir ini. Menurut Stewart (2004) dan Stockwell (2012), metode SRME ini tidak dapat digunakan secara tunggal untuk mengatenuasi berbagai multiple pada berbagai variasi kedalaman. Untuk mengatenuasi multiple secara efektif diperlukan kombinasi berbagai metode dengan kelebihannya masing-masing. Salah satu metode yang dapat dikombinasikan adalah metode radon parabolik.

Dalam penelitian ini akan diaplikasikan metode SRME di Cekungan Bryant Canyon Lepas Pantai Louisiana Texas. Daerah ini dipilih karena merupakan salah satu perairan laut dalam yang mempunyai struktur geologi kompleks, seperti terdapat banyak patahan, lipatan, dan struktur garam. Hal ini memungkinkan munculnya lebih banyak multiple dibandingkan daerah lainnya. Atenuasi multiple untuk data seismik cekungan Bryant Canyon Lepas Pantai Louisiana Texas ini sebelumnya telah dilakukan oleh Saputra dan Namigo (2015) dengan menggunakan metode dekonvolusi prediktif, transformasi radon, dan dekonvolusi tau-P. Dari hasil penelitian, didapatkan bahwa ketiga metode tersebut berhasil mengatenuasi peg-leg multiple, intrabed multiple, dan multiple di sekitar struktur garam namun ketiga metode tersebut tidak berhasil mengatenuasi water-bottom multiple. Pada penelitian ini dilihat keefektifan metode SRME dalam mengatenuasi jenis multiple terutama untuk water-bottom multiple. Selain itu, pada penelitian ini juga dilakukan kombinasi metode SRME dengan radon parabolik untuk dapat menghilangkan multiple secara lebih optimal. Metode radon parabolik dipilih karena cukup efektif untuk menghilangkan multiple far-offset.

\section{METODE}

Penelitian dilakukan dengan menerapkan metode SRME dan kombinasi metode SRME dengan radon parabolik untuk menghilangkan multiple pada Cekungan Bryant Canyon Lepas Pantai Louisiana Texas hasil akuisisi United States Geological Survey (USGS). Dari hasil akuisisi, dipilih empat line berdasarkan bentuk bawah permukaan dengan struktur kompleks dan teridentifikasi noise multiple. Line yang dipilih adalah line 3, line 4, line 12, dan line 13. Data diolah dengan menggunakan perangkat lunak Geomage (trial version).

Metode SRME diterapkan melalui tiga langkah. Langkah pertama meliputi penghapusan noise non fisik melalui keteraturan data untuk mendapatkan konfigurasi sumber seismik dan perekam yang konstan, menghilangkan interpolasi near offsets (jarak antara sumber seismik dan penerima terdekat) dan intermediate offset (jarak antara sumber seismik dan penerima menengah), serta menghapus gelombang langsung dan refleksi gelombang permukaan. Langkah kedua adalah prediksi multiple. Prediksi ini didasarkan pada pengamatan bahwa setiap multiple permukaan dapat diprediksi melalui keteraturan rekaman gelombang dari data itu sendiri. Langkah yang terakhir, input data total dikurangi dengan prediksi multiple, sehingga menghasilkan data yang bersih dari multiple.

Atenuasi multiple menggunakan metode radon parabolik dilakukan dengan memisahkan reflektor primer dan multiple. Teknik radon parabolik dilakukan dalam Common Mid-Point (CMP) gather. Oleh karena itu perlu dilakukan geometri data sehingga diperoleh penomoran CMP. CMP gather yang terkoreksi Normal Moveout (NMO) ditransformasi kedalam domain radon, reflektor primer terkoreksi NMO akan membentuk garis lurus dalam domain $\mathrm{t}-\mathrm{x}$ sedangkan multiple akan membentuk pola parabola. Pola garis lurus kurva parabola ini akan dapat dipisahkan dalam domain radon.

\section{HASIL DAN PEMBAHASAN}

\subsection{Penampang Seismik Line 3}

Penampang seismik pada line 3 terdiri dari tiga reflektor primer yaitu P1, P2, dan P3. Line 3 teridentifikasi mengandung multiple yang terdiri dari, tiga water-bottom multiple (WB1, 
WB3(a), dan WB3(b)), 4 peg-leg multiple (PG2(a), PG2(b), PG3(a), dan PG3(b)), serta 1 intrabed multiple, yaitu IB3 (Gambar 1(a)). Water-bottom multiple diidentifikasi dari perulangan nya terhadap bentuk dasar laut. Peg-leg Multiple diidentifikasi dari perulangan nya terhadap bentuk refleksi primer batuan. Sama halnya dengan peg-leg multiple, intra-bed multiple identifikasi berdasarkan pengulangan refleksi dari reflektor primer, namun biasanya intra-bed multiple terletak diantara peg-leg multiple.

Penampang seismik pada line 3 setelah dilakukan atenuasi dengan metode SRME menunjukkan hasil yang lebih bersih dibandingkan dengan sebelum dilakukan atenuasi (Gambar 1(b)). Hasil atenuasi menunjukkan hilangnya keberadaan WB1(b), PG2, dan WB3(b) pada line 3. Multiple jenis WB1 dan WB3(b), PG3(a) dan PG3(b), serta IB3 tidak dapat hilang setelah diterapkan metode SRME, namun berkurang jika dibandingkan dengan sebelum dilakukan atenuasi. Hal ini menandakan bahwa metode SRME cukup efektif diterapkan pada line 3, terutama untuk mengatenuasi water-bottom multiple dan multiple disekitar near-offset. Selain mengurangi keberadaan multiple, metode SRME juga terbukti dapat menaikan S/N ratio. Reflektor primer yang muncul pada line 3 setelah diterapkan metode SRME terlihat lebih jelas dibandingkan dengan data sebelum diterapkan SRME.

Penerapan kombinasi metode SRME dan radon parabolik terbukti cukup efektif untuk mengatenuasi multiple secara keseluruhan pada line 3. Jenis peg-leg multiple dan intra bed multiple yang masih muncul setelah diatenuasi dengan metode SRME dapat dilemahkan setelah kedua metode ini dikombinasikan. Jenis water-bottom multiple yang masih terlihat pada faroffset hampir sepenuhnya hilang. Hasil ini didapatkan karena metode SRME hanya menghilangkan jenis water-bottom multiple dan multiple pada near-offset. Sedangkan metode radon parabolik efektif digunakan pada multiple far-offset. (Gambar 1(c)).



(a)

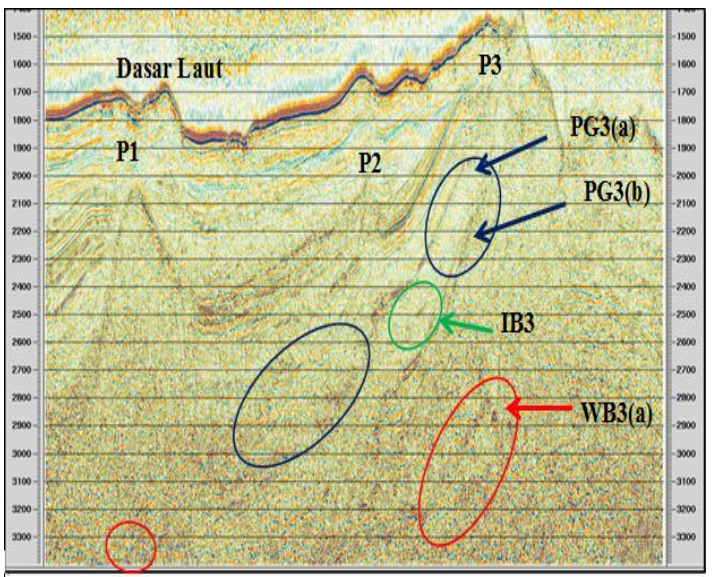

(b)

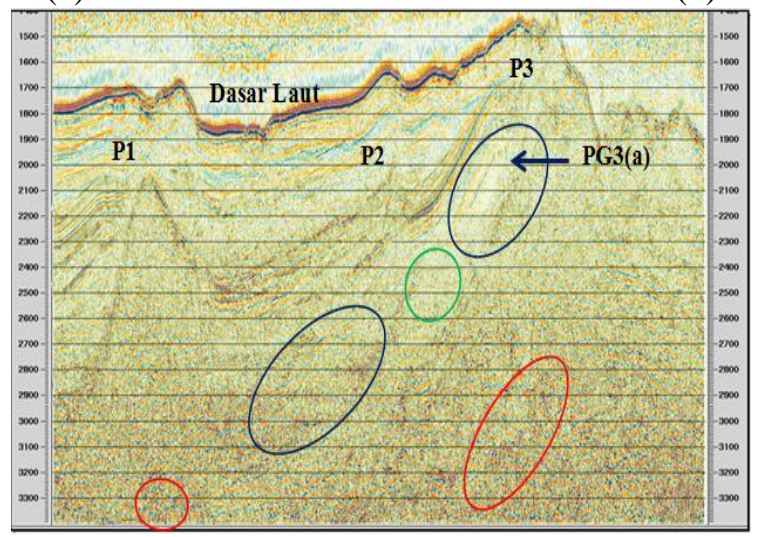

(c)

Gambar 1 Penampang seismik line 3 (a) sebelum atenuasi multiple, (b) setelah penerapan metode SRME, dan (c) setelah penerapan metode SRME + radon parabolik 


\subsection{Penampang Seismik Line 4}

Keberadaan multiple pada line 4 tidak begitu dominan. Terlihat pada Gambar 2(a) line 4 terdiri dari 4 refleksi primer ( $\mathrm{P} 1, \mathrm{P} 2, \mathrm{P} 3$, dan $\mathrm{P} 4)$ yang hanya mengandung beberapa multiple. P1 hanya menghasilkan satu jenis multiple yaitu peg-leg multiple yang mengalami tiga kali pengulangan (PG1(a), PG1(b), dan PG1(c)). P2 menghasilkan satu kali pengulangan yaitu membentuk water-bottom multiple (WB2) seperti yang terjadi pada reflektor 4 (WB4). P3 juga hanya menghasilkan satu kali pengulangan yaitu membentuk peg-leg multiple (PG3). Pada line 4 tidak teridentifikasi keberadaan intra-bed multiple.

Penampang seismik pada line 4 terlihat lebih jelas dan lebih bersih dari multiple setelah dilakukan atenuasi dengan metode SRME (Gambar 2(b)). Hampir seluruh multiple yang terdapat pada line 4 berkurang bahkan hilang terutama untuk multiple near-offset, yaitu PG1(a), PG 1(b), dan PG 1(c), serta WB2. Keberadaan PG3 dan WB4 masih terlihat samar-samar karena tidak hilang seluruhnya namun metode ini berhasil mengurangi keberadaan multiple tersebut. Hal ini menunjukkan bahwa metode SRME efektif diterapkan pada line 4, terutama pada daerah near-offset. Namun hanya mengurangi multiple pada far-offset. Setelah diterapkan metode SRME, reflektor primer pada line 4 terlihat lebih tajam.

Hasil atenuasi dengan menggunakan kombinasi metode SRME dan radon parabolik berhasil menghilangkan multiple pada line 4 secara lebih optimal dibandingkan dengan penerapan metode SRME saja pada. Jenis peg-leg multiple dan multiple far-offset yang tidak dapat dihilangkan hanya dengan menggunakan metode SRME terbukti dapat dihilangkan dengan menggunakan kombinasi kedua metode ini. Hasil kombinasi kedua metode juga berhasil menguatkan kemenerusan dari sinyal primer sehingga didapatkan gambaran penampang seismik yang baik dan bersih dari multiple (Gambar 2(c)).

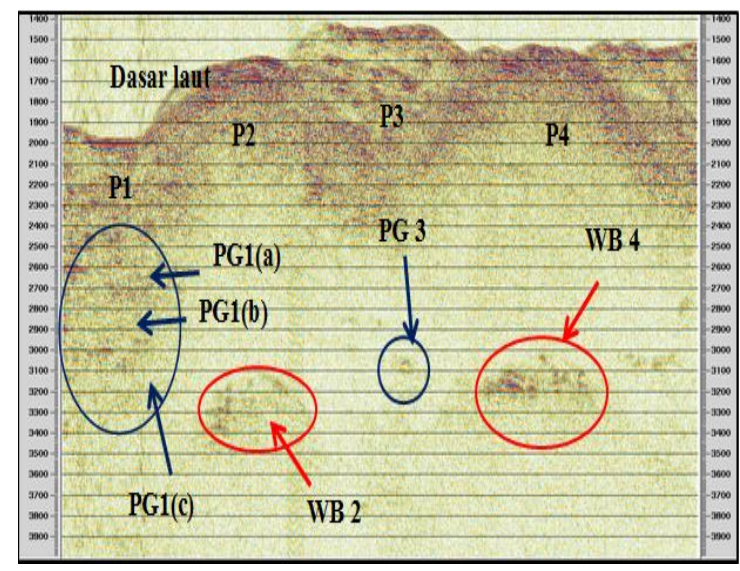

(a)

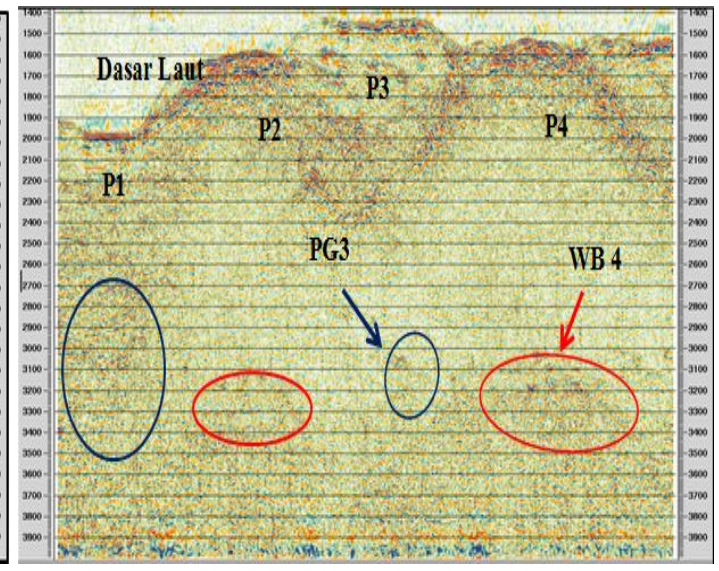

(b)

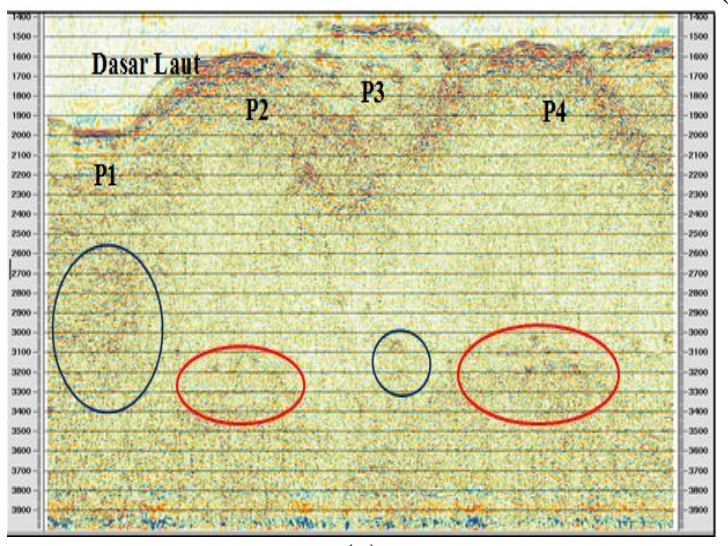

(c)

Gambar 2 Penampang seismik line 4 (a) sebelum atenuasi multiple, (b) setelah penerapan metode SRME, dan (c) setelah penerapan metode SRME + radon parabolik 


\subsection{Penampang Seismik Line 12}

Penampang seismik line 12 mempunyai tiga reflektor primer (P1, P2, P3) dan teridentifikasi mengandung banyak multiple (Gambar 3(a)). P1 menghasilkan water-bottom multiple yang mengalami tiga kali pengulangan, yaitu WB1(a), WB1(b), dan WB1(c) dan P2 hanya menghasilkan satu kali pengulangan peg-leg multiple, yaitu PG2. Berbeda dengan P2, P3 menghasilkan lebih banyak multiple. Jenis multiple yang terdapat pada P3 yang terdiri dari water-bottom multiple dengan dua kali pengulangan, peg-leg multiple dengan empat kali pengulangan dan intra-bed multiple dengan satu kali pengulangan saja.

Penerapan metode SRME pada line 12 terbukti cukup efektif untuk mengurangi keberadaan multiple (Gambar 3(b)). Metode SRME dapat menghilangkan jenis water bottom multiple secara hampir keseluruhan kecuali untuk WB3(b) dan mengurangi jenis PG2 dan PG3. Hal ini membuktikan bahwa metode SRME cukup efektif untuk menghilangkan water-bottom multiple pada line 12 yang tidak dapat dihilangkan oleh metode lainnya. Selain itu metode SRME juga berhasil menguatkan S/N ratio yang menghasilkan lapisan primer yang lebih tajam.

Hasil atenuasi dengan menggunakan kombinasi metode SRME dan radon parabolik terbukti efektif untuk mereduksi keberadaan multiple. Multiple yang tidak dapat diatenuasi oleh metode SRME, seperti peg-leg multiple dan multiple far-offset dapat diminimalisir dengan mengkombinasikan kedua metode ini. Kombinasi kedua metode ini pada line 12 menghasilkan gambaran penampang seismik yang bersih dan tajam. Kombinasi metode ini masih menghasilkan beberapa multiple, terutama multiple far-offset.

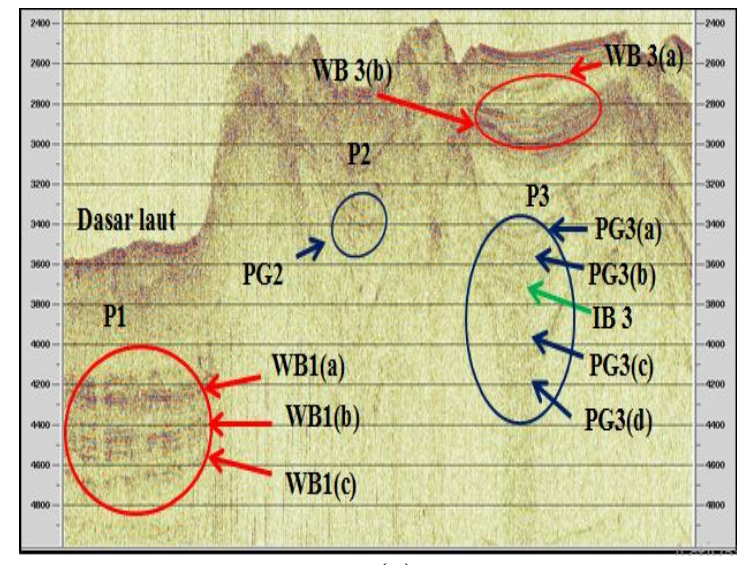

(a)

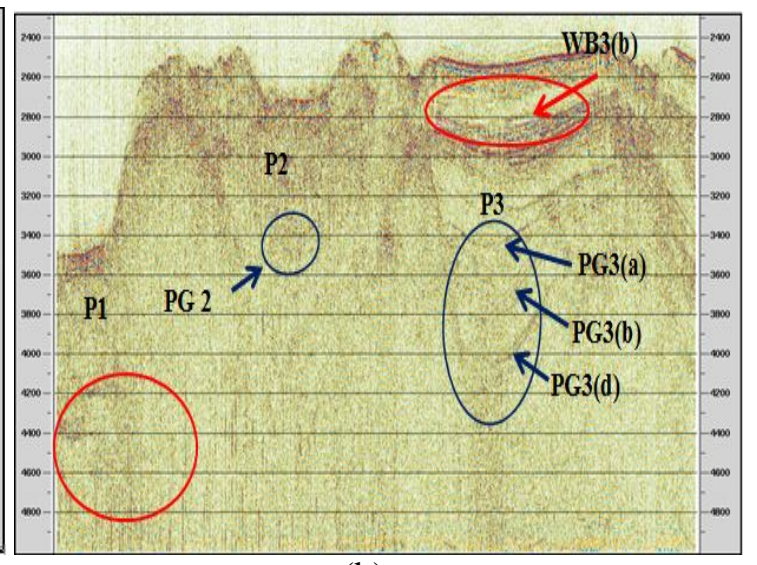

(b)

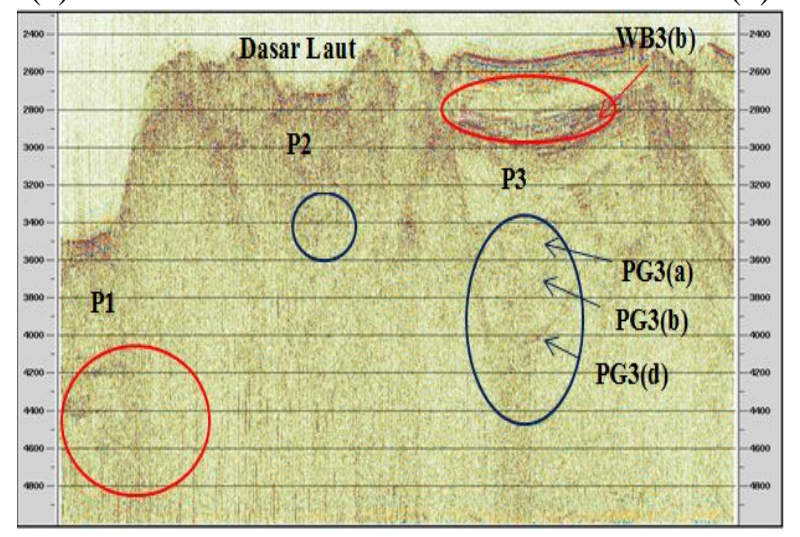

(c)

Gambar 3 Penampang seismik line 12 (a) sebelum atenuasi multiple, (b) setelah penerapan metode SRME, dan (c) setelah penerapan metode SRME + radon parabolik

\subsection{Penampang Seismik Line 13}

Penampang seismik pada line 13 di dominasi oleh adanya peg-leg multiple (Gambar 4(a)). P1 menghasilkan PG1 dan WB1. P2 hanya menghasilkan satu kali pengulangan peg-leg 
multiple, yaitu PG2. P3 menghasilkan peg-leg multiple namun dengan empat kali pengulangan, yaitu PG3(a), PG3(b), PG3(c), dan PG3(d).

Penerapan metode SRME dapat mengurangi keberadaan multiple pada line 13 (Gambar 4(b)). Setelah dilakukan atenuasi, jenis WB1 dan PG2 dapat teratenuasi dengan baik bahkan hilang, sedangkan untuk jenis peg-leg multiple tidak dapat di atenuasi dengan baik oleh metode SRME ini, namun dapat mengurangi keberadaan multiple tersebut. Hal ini membuktikan bahwa metode SRME hanya efektif digunakan untuk menghilangkan multiple jenis water-bottom multiple dan multiple yang terdapat di sekitar near-offset.

Hasil atenuasi dengan menggunakan kombinasi metode SRME dan radon parabolik menunjukkan bahwa kedua kombinasi metode tersebut cukup efektif untuk menghilangkan jenis multiple secara keseluruhan pada line 13 (Gambar 4(c)). Jenis peg-leg multiple pada line 13 yang tidak dapat di hilangkan hanya dengan metode SRME berhasil dikurangi keberadaanya dengan mengkombinasikan metode SRME dengan metode radon parabolik. Kombinasi kedua metode ini berhasil meningkatkan $\mathrm{S} / \mathrm{N}$ to ratio sehingga di dapatkan hasil penampang seismik yang baik dan bersih dari multiple.

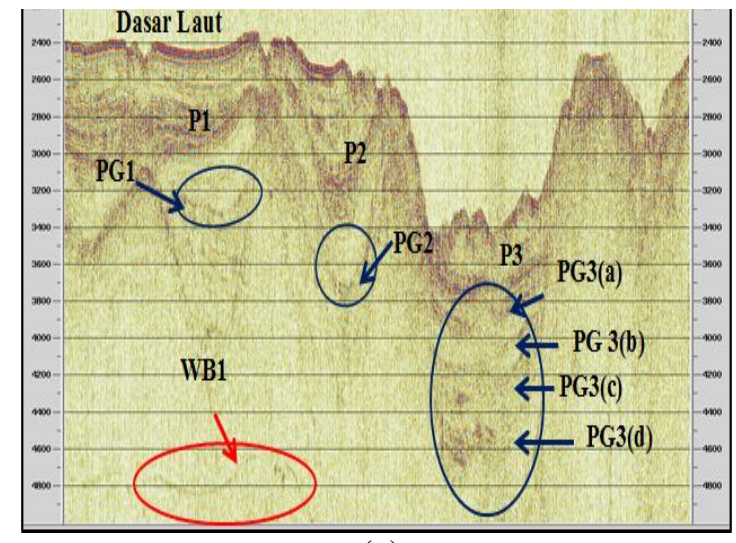

(a)

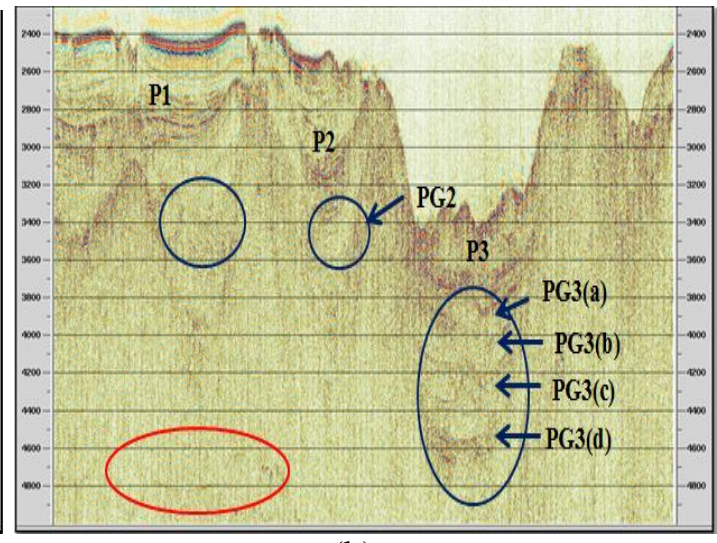

(b)

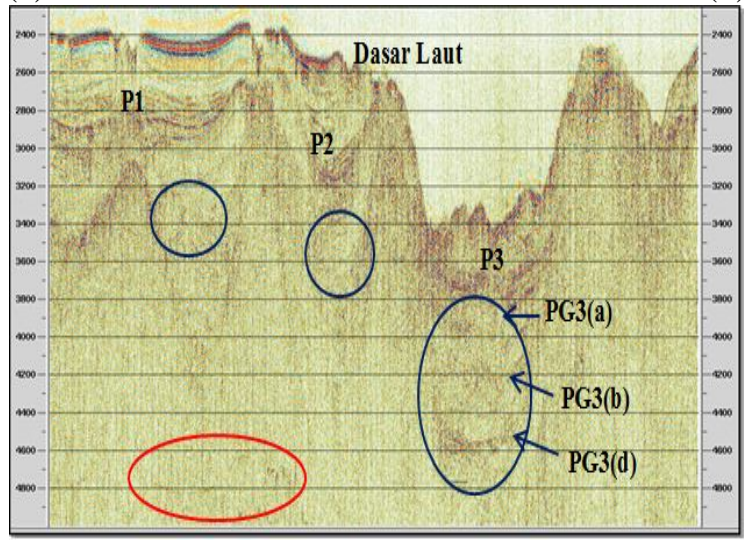

(c)

Gambar 4 Penampang seismik line 13 (a) sebelum atenuasi multiple, (b) setelah penerapan metode SRME, dan (c) setelah penerapan metode SRME + radon parabolik

\section{KESIMPULAN}

Dari penelitian yang telah dilakukan, dapat ditarik kesimpulan bahwa data seismik 2D Cekungan Bryant Canyon Lepas Pantai Louisiana Texas teridentifikasi mengandung banyak multiple, diantaranya water-bottom multiple, peg-leg multiple, dan intra-bed multiple. Penerapan metode Surface Related Multiple Elimination (SRME) pada line 3, line 4, line 12, dan line 13 penampang seismik 2D Bryant Canyon Lepas Pantai Louisiana Texas efektif mengatenuasi water-bottom multiple yang tidak dapat dihilangkan dengan metode konvensional lainnya. Metode SRME juga berhasil mengurangi multiple pada daerah near-offset. Kombinasi metode Surface Related Multiple Elimination (SRME) dengan metode radon parabolik dapat diterapkan untuk mengatenuasi multiple secara lebih optimal. Kombinasi kedua metode ini 
terbukti lebih efektif untuk menghilangkan multiple pada data seismik 2D cekungan Bryant Canyon Lepas Pantai Louisiana Texas dibandingkan dengan penerapan tunggal SRME saja.

\section{DAFTAR PUSTAKA}

Badley, M.E., 1947, Practical Seismic Interpretation, International Human Resource Development Corporation, Boston.

Peacock, K.L., B.,dan Treitel, S., 1969, Predictive Deconvolution: Theory and Practice, Geophysics, 34.

Saputra, A., dan Namigo, E.L., 2015, Atenuasi Multiple Berbasis Seismic Unix Pada Data Seismik 2D Cekungan Bryant Canyon Lepas Pantai Teluk Louisiana Texas, Jurnal Fisika Unand, Vol. 4, No. 4, Jurusan Fisika Universitas Andalas, Padang.

Stockwell, J. W., 2012, A Course in Geophysical Image Processing with Seismic Unix: GPGN 461/561 Lab Fall 2012, Research Associate Center for Wave Phenomena.

Stewart, P., 2004, Multiple attenuation technique suitable for varying water depths, GX Technology, Canada and Beyond

Verschuur, D.J., Berkhout, A.J, Wapenaar, 1992, Adaptive Surface Related Multiple Elimination, Geophysics, 64, 1166-1177.

Yilmaz.Ö.,1987, Seismic Data Analysis: Processing, Inversion, and Interpretation of Seismic Data, Volume I, Geophys. Prosp., USA. 